\title{
Book Review : The Kingdon Field Guide to African Mammals, by Jonathan Kingdon
}

\section{$\operatorname{AUTHOR}(\mathrm{S})$ :}

Huffman, Michael A.

\section{CITATION:}

Huffman, Michael A.. Book Review: The Kingdon Field Guide to African Mammals, by Jonathan Kingdon. Pan Africa News 1997, 4(1): 8-8

ISSUE DATE:

1997-06

URL:

http://hdl.handle.net/2433/143347

RIGHT:

Copyright (C) Pan Africa News. 


\section{Book Review}

The Kingdon Field Guide to African Mammals, by Jonathan Kingdon, Natural World Series, Academic Press, Harcourt \& Brace Publishers, 1997 UK 29.95 GBP, US $\$ 39.95$ paperback.

Jonathan Kingdon's Field Guide to African Mammals is definitely a grade above the rest and takes the lead in bringing in a new era of field guides. Even if you are not ready to retire your old field guide or are looking for your first, I highly recommend all to consider this one.

The guide is very user friendly. Provided at the beginning of the book is a complete indexed species checklist, containing all 1150 currently recognized species and subspecies. Treatment of the primates is good and, as the acknowledgments attest, has benefited from the advise and experience of a number of leading primatologists. The book starts off with the Order Primates and includes updated information and coverage of all the newly recognized species of bushbaby, baboons, guenons and mangabeys, and colobus monkeys. Being so new, however, there are probably a few minor points still open to argument.

Unlike the other standard travel sized field African mammal guides available, the plates and maps are placed with the text descriptions of each species, so there is no flipping through the book looking for a face to go with the name and description. Many of the listings include black and white drawings to supplement the colored species portraits which detail diagnostic morphological and or behavioral patterns. Subspecies distributions are listed together on the same maps and are color coded. When appropriate, the illustrations of related species or subspecies are brilliantly placed together in an array on one plate for easy comparison.

Each species description is rich in detail and consists of: common name, currently recognized species name (earliest $\mathrm{sp}$. name or syn. when appropriate), other common names in French, German and often Swahili or Lingala, measurements, recognizing characteristics, subspecies, distribution, habitat, food, behavior, adaptations (physical \& ecological) and a statement of the species current conservation status based on World Conservation Union, CITES, IUCN reports and or contemporary expert consensus.

This volume is likely the most complete and up to date travel size field guide available on African mammals. A finely illustrated discussion of the African environment, climate, natural history and geography is provided at the back. A lot of material is packed into its handy size (14 $\mathrm{cm} \times 21.5 \mathrm{~cm} \times 2.5 \mathrm{~cm}, 750 \mathrm{~g}$ ). Given the authoritative and broad scope of the material covered, this book would also serve well as a desk reference and educational tool in the classroom.

Besides being a very unique and remarkable field guide, it will provide hours of reading and viewing enjoyment. It is truly a work of art, a pleasure to the eye from start to finish.

Michael A. Huffman

Primate Research Institute, Kyoto University

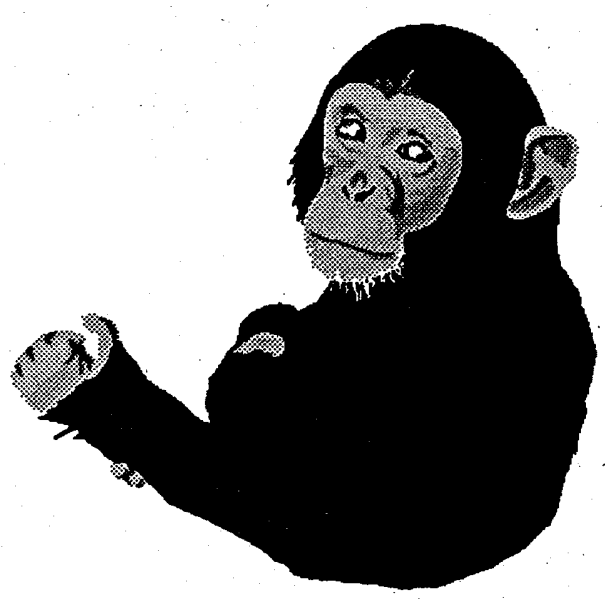

Illustration by Michio NaKamura 